\title{
Stenosis of the Main Artery Supplying an Organ: Effect of End-Organ Vascular Compliance on the Poststenotic Peak Systolic Velocity
}

\author{
Ronald O. Bude, MD, Jonathan M. Rubin, MD, PhD
}

Prior studies have shown variable results using poststenotic peak systolic velocity to detect hemodynamically significant renal artery stenoses. We postulated that vascular compliance, which affects the arterial waveform and varies by a factor of at least 5 in vivo, affects the peak systolic velocity, perhaps explaining the aforementioned variable results using peak systolic velocity to detect stenoses. A hydraulic model was used to investigate the relationship between end-organ vascular compliance and the peak systolic velocity. The peak systolic velocity was found to be mildly dependent on vascular compliance, decreasing with decreasing compliance. These results help explain some of the reported variability using peak systolic velocity to detect hemodynamically significant renal artery stenoses, but the effect is not great enough to explain the variability completely. Other factors not investigated in this study must exist that also affect peak systolic velocity. KEY WORDS: Blood, flow dynamics; Phantoms; Renal arteries, flow dynamics; Kidney, arterial stenosis; Stenosis, renal artery.
$\mathrm{V}$ ascular compliance affects the arterial waveform. ${ }^{1-4}$ Vascular compliance also varies in vivo by a factor of at least $5.5-11$ We postulated that vascular compliance affects the poststenotic waveform and thus the poststenotic PSV

\section{ABBREVIATIONS}

PSV, Peak systolic velocity; ID, Inside diameter; OD, Outside diameter; RC, Resistive-capacitive; RI, Resistive index; PRF, Pulse repetition frequency; RAR, Ratio of renal artery to aortic peak systolic velocity; SD, Standard deviation

\footnotetext{
Received March 3, 1999, from the Department of Radiology, University of Michigan Medical Center, Ann Arbor, Michigan. Revised manuscript accepted for publication May 22, 1999.

Address correspondence and reprint requests to Ronald Bude, MD, Department of Radiology, TC 2910K, University of Michigan Medical Center, 1500 East Medical Center Drive, Ann Arbor, MI 48109-0326.
}

obtained during Doppler sonography in cases of hemodynamically significant arterial stenosis. If so, this might help explain the variable results reported previously in the sonographic detection of hemodynamically significant renal arterial stenoses using the poststenotic PSV. ${ }^{12-30}$ An in vitro hydraulic model was developed and experiments were performed to evaluate the effect of end-organ vascular compliance on the poststenotic PSV.

\section{MATERIALS AND METHODS}

\section{Hydraulic Model}

A general discussion of the model is presented here, with specifics discussed in subsequent sections. The model (Fig. 1) was constructed to study the effect of end-organ vascular compliance on the poststenotic PSV of a stenosed artery supplying an organ such as 


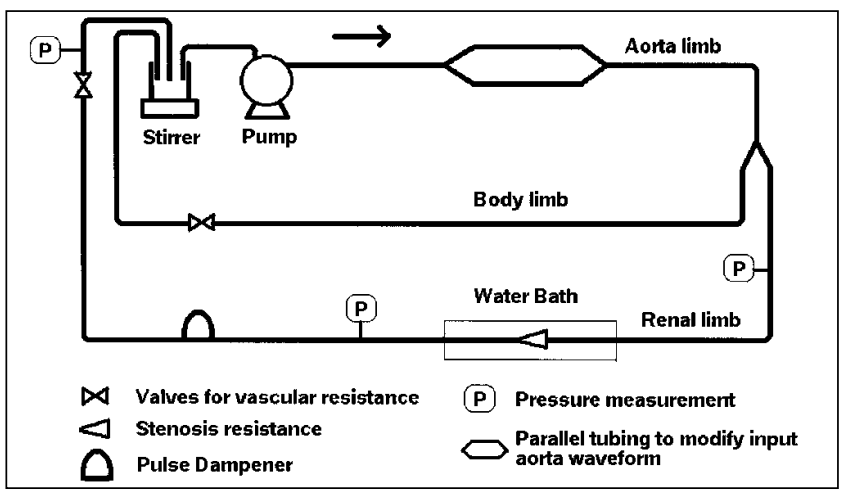

Figure 1 Schematic diagram of the experimental design.

the kidney. A pulsatile pump supplied flow through a single tube, representing the descending aorta, which branched; one branch simulated blood flow to the kidney and the other simulated blood flow to the rest of the body. (For the remainder of this study, these components will be referred to as "aorta," "renal" or "kidney," and "body" for clarity and brevity, acknowledging that this is an in vitro rather than an in vivo study.) This set-up allowed flow to be diverted from the kidney to the rest of the body when the model was changed from normal to high renal vascular resistance, as happens in vivo. Four experimental runs were performed, two with a low grade stenosis and two with a moderate grade stenosis inserted into the renal branch. For each stenosis, PSV values were obtained immediately downstream from the stenosis at end-organ compliances ranging from very low to normal, at two different degrees of renal vascular resistance: (1) a resistance allowing approximately $10 \%$ of volume flow through the kidney ("normal" resistance), (2) a resistance allowing approximately $2 \%$ of volume flow through the kidney ("high" resistance).

\section{Pump and Pump Output Tubing}

A constant volume pump (Model 1421; Harvard Apparatus, Millis, MA) supplied pulsatile flow through a single $0.95 \mathrm{~cm}(3 / 8$ inch) ID, $1.43 \mathrm{~cm} \mathrm{(9/16}$ inch) OD vinyl tube, at fixed settings throughout the experiment: 60 strokes/min; $10 \mathrm{ml} /$ stroke; duty cycle (systolic fraction of the cardiac cycle) of 0.3 . Because the pump output was very pulsatile without diastolic flow and the resultant renal artery waveform did not simulate a normal in vivo renal artery waveform, the fluid-flow analogue of an RC circuit ${ }^{31}$ was installed immediately downstream from the pump to modify the pump output waveform. By adjusting the position and degree of stenoses of clamps on the two parallel lengths of gum rubber tubing $(0.79 \mathrm{~cm} \mathrm{[5/16}$ inch] ID, $1.11 \mathrm{~cm} \mathrm{[7/16} \mathrm{inch]} \mathrm{OD)}$ 24 and $45 \mathrm{~cm}$ long (Fig. 1) that composed this network, it was possible to produce a renal artery waveform, with diastolic flow, that simulated an in vivo renal artery waveform. An RI, as measured with electronic calipers on the monitor of the ultrasound unit, of 0.54 was chosen as the input prestenotic renal artery RI for both the low and the moderate grade stenoses at normal renal vascular resistance because this value was within the physiologic range and was the highest RI the model could produce. Subsequent, more accurate measurement of the RI by hand with calipers from the films showed the input RI values to be $0.53 \pm 0.02$ for the moderate grade stenosis and $0.54 \pm 0.02$ for the low grade stenosis.

\section{Aorta, Renal, and Body Branches}

Distal to the RC network, the descending aorta was simulated with $0.64 \mathrm{~cm}(1 / 4$ inch) ID, $0.95 \mathrm{~cm}(3 / 8$ inch) OD vinyl tubing, which branched into the body branch, composed entirely of the same tubing as the aorta, and the renal branch (to be discussed shortly). Needle valves (Catalogue \#6393-60; Cole Parmer Instrument, Vernon Hills, IL) near the ends of these branches simulated the total vascular resistances of the body and the kidney. The renal and body resistances were adjusted at the beginning of each experimental run so that: (1) the mean pressures in the renal artery proximal to the stenoses were as close to physiologic as the model allowed, ranging from 7.33 $\times 10^{3}$ to $1.36 \times 10^{4} \mathrm{~Pa}$ (55 to $102 \mathrm{~mm} \mathrm{Hg}$ ) during the entire experiment, and (2) approximately $10 \%$ of pump output flowed through the renal branch at normal resistance (actually 10.3\% [0.677 cc/s renal flow $/(0.677 \mathrm{cc} / \mathrm{s}$ renal flow $+5.87 \mathrm{cc} / \mathrm{s}$ body flow $)]$ for both low and moderate grade stenoses), since the normal kidney receives approximately $10 \%$ of cardiac output 32 and approximately $2 \%$ (actually $1.88 \%$ $[0.138 \mathrm{cc} / \mathrm{s}$ renal flow $/(0.138 \mathrm{cc} / \mathrm{s}$ renal flow +7.19 $\mathrm{cc} / \mathrm{s}$ body flow)] for both low and moderate grade stenoses) flowed through the renal branch at high resistance. Once set at the beginning of each experimental run, neither the renal nor the body resistance valves were adjusted for the remainder of that run.

The proximal renal branch, from the aorta through the stenosis region, was composed of the same vinyl tubing as the aorta through which Doppler sonography could be successfully performed. The remainder of the renal branch was composed of stiff polypropylene tubing (to simulate as closely as possible zero compliance in this portion; the tubing was so stiff that it could not be perceptibly compressed by hand, and intraluminal signals could not be obtained 
because the ultrasound beam could not sufficiently penetrate the tubing), $0.64 \mathrm{~cm} \mathrm{(1/4} \mathrm{inch)} \mathrm{ID} \mathrm{and} 0.95$ $\mathrm{cm}(3 / 8$ inch) OD, with the following exceptions: (1) the stenoses, (2) the compliance region (pulse dampener) (Fig. 1), (3) a $27 \mathrm{~cm}$ segment of vinyl tubing immediately proximal to the distal resistance valve, which provided an insonation port when necessary, and (4) short lengths of vinyl tubing to allow leak-free placement of pressure monitor needles (silicone caulk prevented leakage at vinyl tubing, but no method could be found to prevent leakage at polypropylene tubing). Polypropylene tubing was bent to fit the model by softening it in near-boiling water, and allowing it to cool, and set, in place. Flow through the body and kidney branches returned to a common reservoir on top of a mechanical stirrer (Magnestir; A. S. Aloe, St. Louis, MO). Renal artery pressures upstream from the stenosis, downstream from the stenosis but upstream from the renal vascular resistance valve, and downstream from the renal vascular resistance valve were measured with pressure transducers (Transpac IV; Abbott Critical Care Systems, Abbott Laboratories/Hospital Products Division, North Chicago, IL) connected to a monitor (Model 78354A; Hewlett-Packard, Bad Homburg, Germany) (Fig. 1).

\section{Interchangeable Renal Artery Stenoses}

Two renal artery "stenoses" were made with $23 \mathrm{~mm}$ long segments of copper tubing, 0.7 and $2.5 \mathrm{~mm}$ ID, which produced $61 \%$ and $89 \%$ diameter stenoses in the $0.64 \mathrm{~cm}(1 / 4$ inch) ID vinyl tubing. These were glued into centrally drilled holes in $2 \mathrm{~cm}$ lengths of $0.79 \mathrm{~cm}(5 / 16$ inch) diameter wooden dowel, the surfaces of which were carefully painted to preclude water absorption or exudation, so that the tubing edges extended from the cut surfaces of the dowel plugs approximately $1.5 \mathrm{~mm}$ on each side. Spectral Doppler sonography was performed immediately distal to the copper tubing edges, which could be clearly seen sonographically. Color or power Doppler sonography of the poststenotic jet was used to determine the insonation angle. The wooden dowel segments produced a water-tight slide fit in the $0.64 \mathrm{~cm}(1 / 4$ inch) ID vinyl tubing, which facilitated stenosis interchanges. At the beginning of the experiment, at normal renal vascular resistance, pressure gradients across the stenoses and across the renal resistance valves were measured to determine the relative hemodynamic significance of the stenoses. Under the conditions of this experiment, the pressure gradient across the $61 \%$ diameter stenosis was $6 \%$ of the total pressure drop across the renal branch $\left(6.7 \times 10^{2} \mathrm{~Pa}\right.$ [5 mm Hg] $)$ pressure drop across the stenosis; $1.16 \times 10^{4} \mathrm{~Pa}(87 \mathrm{~mm} \mathrm{Hg})$ total pressure drop across the renal limb; percentage pressure drop in stenosis $=5 / 87=6 \%$ ), and the pressure gradient across the $89 \%$ diameter stenosis was $38 \%$ of the total pressure drop across the renal branch $\left(4.80 \times 10^{3} \mathrm{~Pa}\right.$ [36 $\mathrm{mm} \mathrm{Hg}$ ] pressure drop across stenosis; $1.25 \times 10^{4}$ $\mathrm{Pa}(94 \mathrm{~mm} \mathrm{Hg})$ total pressure drop across the renal limb; percentage pressure drop in stenosis $=36 / 94=$ $38 \%$ ). In the normal human, the mean arterial pressure is approximately $1.33 \times 10^{4} \mathrm{~Pa}(100 \mathrm{~mm} \mathrm{Hg})^{33}$; therefore, transstenotic pressure gradients of $6 \%$ and $38 \%$ would represent absolute pressure drops, given a mean pressure of $1.33 \times 10^{4} \mathrm{~Pa}(100 \mathrm{~mm} \mathrm{Hg})$, of 8.0 $\times 10^{2}$ and $5.07 \times 10^{3} \mathrm{~Pa}(6$ and $38 \mathrm{~mm} \mathrm{Hg})$, respectively. In our institution, a pressure drop of $8.0 \times 10^{2}$ $\mathrm{Pa}(6 \mathrm{~mm} \mathrm{Hg})$ is low grade and slightly below the level for angioplasty or stenting $\left(1.33 \times 10^{3} \mathrm{~Pa}[10\right.$ $\mathrm{mm} \mathrm{Hg]}$ ), whereas a pressure drop of $5.07 \times 10^{3} \mathrm{~Pa}$ (38 $\mathrm{mm} \mathrm{Hg}$ ) is moderately elevated. On the basis of these results, these stenoses will be referred to as "low" and "moderate" grades throughout the remainder of this experiment.

\section{Renal Artery Compliance}

A pulse dampener (\#07596-20; Cole Parmer Instrument, Vernon Hills, IL), a hollow plastic container roughly the shape of a half sphere resting on its flat surface (Fig. 1), was used to provide finite compliance downstream to the stenosis, which simulated the normal compliance of the renal vasculature. Air introduced through a valve inserted into the top of this device collects at the top while liquid flows, unmixed with air, through the base. The entrapped air compresses during systole and expands during the lower pressure of diastole, thus absorbing some of the flow pulsatility. If the quantity of air is large enough, highly pulsatile flow can be completely converted to steady, nonpulsatile flow. This device is termed a "Windkessel," which is well known in the physiology literature and was first described by Hales in 1733. ${ }^{34}$ Trial and error adjustment of the amount of air in the Windkessel determined that 1.3 cc of air for the low grade stenosis and $3.0 \mathrm{cc}$ of air for the high grade stenosis were needed to damp the input prestenotic renal artery RI from the initial values of 0.53 or 0.54 to near nonpulsatility (an RI of 0.2 ) at normal renal vascular resistance. An RI of 0.2 was chosen rather than an RI of 0.0 because at very low RI values it is extremely difficult to measure the RI accurately, and an RI of 0.2 was so nearly nonpulsatile that this was considered adequate to simulate the degree of pulsatility damping that happens when flow progresses from the pulsatile renal arteries to the essentially nonpulsatile capillaries, yet it was still 
pulsatile enough to be measured, and reproduced, accurately. An RI of 0.54 as measured on the ultrasound unit monitor was chosen as the input RI because it was within the physiologic range and was the largest RI the model could produce. These amounts of air (1.3 cc and $3.0 \mathrm{cc}$ for the low and moderate grade stenoses, respectively) therefore represented "normal" vascular compliance in the model, and compliances were varied in the experimental runs (described later) from very close to zero (absence of air in the Windkessel) to, or slightly greater than, the amounts of air representing the "normal compliance" values.

\section{Inlet Lengths of Tubing}

A flow perturbation (e.g., bifurcation, stenosis, tight turn) transiently alters the flow profile for a variable distance, up to a maximum length known as the inlet length. 35 Since the nonpulsatile, laminar flow inlet length is longer than the inlet lengths for other types of flow, it was used to ensure Doppler measurements were performed in areas of stable flow, with all sonographic examinations and pressure measurements performed at least one inlet length from any flow perturbation, except for the poststenotic PSV, which was obtained in the poststenotic jet at the distal orifice of the stenosis. The nonpulsatile, laminar flow inlet length is defined as follows: $\mathrm{L}=2 \mathrm{kVr}^{2} / v$, where $\mathrm{L}$ is inlet length in $\mathrm{cm}, \mathrm{k}$ is an experimentally derived constant (0.08), $\mathrm{V}$ is mean velocity in $\mathrm{cm} / \mathrm{s}, \mathrm{r}$ is tube radius in $\mathrm{cm}$, and $v$ is kinematic viscosity in stokes $\left(\mathrm{cm}^{2} / \mathrm{s}\right) \cdot 35$

\section{Blood Mimicking Liquid}

The model was filled with $1500 \mathrm{ml}$ of a solution with the mean viscosity of blood (2.5 centipoise $\left.{ }^{36}\right)$, composed of $35 \mathrm{ml}$ of glycerol and $0.67 \mathrm{~g}$ of microparticles (Sephadex G-50; Sigma Chemical, St. Louis, MO) as ultrasound beam scatterers for every $100 \mathrm{ml}$ of water. ${ }^{37}$ Green food coloring was used to tint the fluid so air bubbles could be seen and eliminated from the nearly opaque, white tubing, since bubbles cyclically changed volume with the cardiac cycle, causing undesirable and unmeasurable compliance.

\section{Doppler Sonography}

A free-standing aluminum frame supported the ultrasound transducers (Spectra; Diasonics, Santa Clara, CA). Doppler waveforms were obtained with $5.0 \mathrm{MHz}$ curvilinear transducers (Doppler frequency $=4.0 \mathrm{MHz}$ ) at gains at which noise first became apparent and at PRF values sufficient to prevent aliasing, at the aorta (moderate grade stenosis: 48 degrees insonation angle, $4.0 \mathrm{KHz}$ PRF, $105 \mathrm{~Hz}$ wall filter; low grade stenosis: 48 degrees insonation angle, 2.9 to $6.0 \mathrm{KHz} \mathrm{PRF}, 75$ to $160 \mathrm{~Hz}$ wall filter), in the renal artery proximal to the stenosis (48 degrees insonation angle, $1.4 \mathrm{KHz}$ PRF, $35 \mathrm{~Hz}$ wall filter), and at the distal orifice of the stenosis (moderate grade stenosis: 48 degrees insonation angle, 16.6 to 22.2 $\mathrm{KHz}$ PRF, 440 to $590 \mathrm{~Hz}$ wall filter; low grade stenosis: 48 degrees insonation angle, 4.0 to $6.0 \mathrm{KHz}$ PRF, 105 to $160 \mathrm{~Hz}$ wall filter). Color and power Doppler sonography ensured accurate angle correction for spectral Doppler sonography in the poststenotic jet. Renal artery sonography was performed in a water bath (wallpaper soaking tray); water-filled plastic bags (acting as interfaces between transducer and tubing) and ultrasound gel were used for sonography at other sites. A sound-absorbent material (Sorbothane [70 durometer]; Sorbothane, Kent, $\mathrm{OH}$ ) interposed between the tubing and its resting surfaces reduced ultrasound wave reverberations.

PSV and RI values were measured by hand using calipers, with RI values calculated according to the following formula: $\mathrm{RI}=(\mathrm{S}-\mathrm{D}) / \mathrm{S}$; where $S=$ height of the systolic peak and D = height of the end diastolic trough. All reported PSV and RI values were means, obtained by averaging the values for four consecutive waveforms (for RI) or five consecutive waveforms (for PSV). The Doppler scale that produced the largest possible waveform without aliasing was used to decrease measurement error.

\section{Validation of Expected Findings}

We expected that downstream from the stenosis, without air in the Windkessel, the model would have very little compliance. Vascular compliance is defined as $\Delta \mathrm{V} / \Delta \mathrm{P}(\mathrm{V}=$ volume; $\mathrm{P}=$ pressure $)$. It is a dynamic phenomenon that could not be measured. Therefore, an indirect method was used to determine if our model had appreciable compliance in the very low compliance mode. Vascular compliance, in conjunction with vascular resistance, causes the progressive damping of pulsatility that occurs as flow progresses from the highly pulsatile central arteries to the essentially nonpulsatile capillaries. ${ }^{1-4}$ Therefore, our model in the very low compliance mode (absence of air in the Windkessel) can be assumed to have very low compliance, lower than that occurring in vivo, if the RI in the distal renal artery just proximal to the resistance valve and downstream to the airless Windkessel (this location corresponds to the very small arteriolar or capillary region in vivo) is 
nearly the same as the RI in the proximal renal artery during maximum flow. Waveforms at the input and output portions of the renal segment of our model without renal artery stenosis and without air in the Windkessel at 10\% renal volume flow had RI values of $0.54 \pm 0.02$ and $0.47 \pm 0.04$ (Fig. 2), respectively, indicating that the compliance in this mode was very low, much lower than occurs in vivo. For data display and analysis (Fig. 3), PSV values obtained at this very low compliance are plotted as if the compliance were zero.

\section{Experimental Runs}

Windkessel compliance is proportional to the amount of air in it, as discussed in the Appendix. Four experimental runs were performed: runs at both normal and high renal vascular resistance for both the low and moderate grade stenoses. For all runs the compliance of the renal arterial bed was varied from very low to normal in the following way: For the moderate grade stenosis, the amount of air in the Windkessel varied from 0 cc (very low compliance) to $3.0 \mathrm{cc}$ (normal compliance), using volumes of $0,0.4,0.8,1.3,2.0$, and $3.0 \mathrm{cc}$. For the

Figure 2 Waveforms used to validate the assumption that the renal vascular limb, without any air in the Windkessel and without a proximal stenosis, had very low compliance. Waveforms in the top row were obtained in the proximal renal artery; the RI was $0.54 \pm 0.02$. Waveforms in the bottom row were obtained in the distal renal vasculature distal to the airless Windkessel; the RI of these downstream waveforms was $0.47 \pm 0.04$. Owing to the minimal decrease in RI between the two sets of waveforms, there is very low compliance in the renal limb of the model without air in the Windkessel, as discussed in the Methods section.

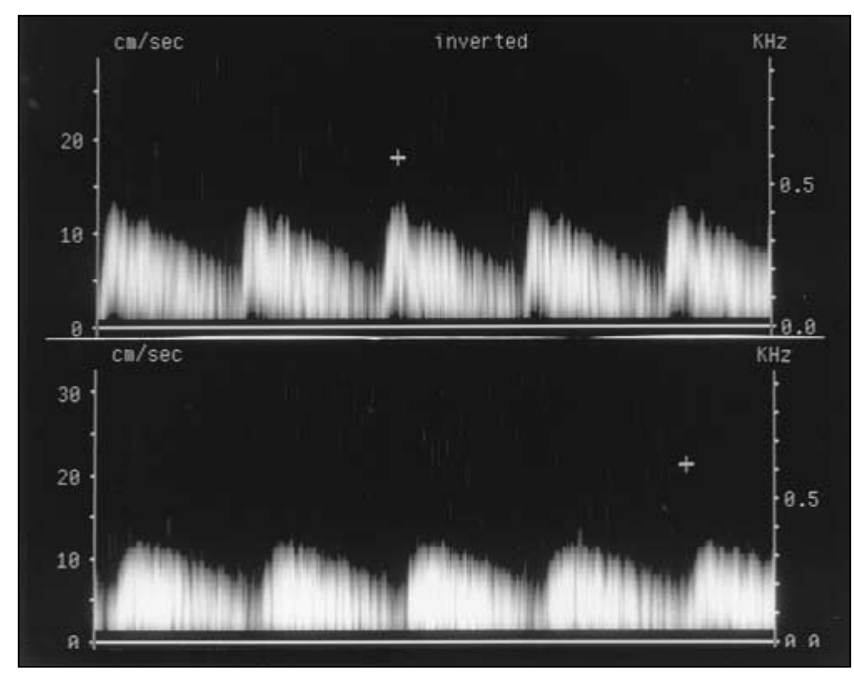

low grade stenosis, the amount of air in the Windkessel was varied from 0 to $1.5 \mathrm{cc}$ in $0.3 \mathrm{cc}$ increments, using air volumes of $0.0,0.3,0.6,0.9$, 1.2 , and $1.5 \mathrm{cc}$. Although the final air volume of 1.5 cc exceeded the $1.3 \mathrm{cc}$ value for normal compliance in the low grade stenosis set-up, this is not important because once the PSV values were plotted as a function of compliance and a curve fitted to the data, all conclusions were drawn from the data spanning the 0 to $1.3 \mathrm{cc}$ increment. For each stenosis, the run at normal renal vascular resistance was performed first, using a renal artery RI proximal to the stenosis of 0.53 or 0.54 , as discussed earlier. This run was followed by the run at high renal vascular resistance. When the switch was made from normal to high renal vascular resistance, the input renal artery RI was not adjusted, as it was for the beginnings of the normal resistance runs, but was allowed to increase as the renal vascular resistance increased, as it does in vivo (the input renal artery RI was 1.0 for runs with both stenoses at high renal vascular resistance).

\section{Data Analysis}

The aortic PSV values varied slightly during each run of the experiment (Table 1). This variation caused the poststenotic PSV to vary independently of distal compliance and resistance. To counteract this effect and to facilitate comparison, all poststenotic PSV values were normalized by dividing the poststenotic PSV by the corresponding aortic PSV. Normalized poststenotic PSV values were plotted versus fractional compliance (normal compliance $=1.0$ ) for both values of renal vascular resistance for each stenosis, and linear curve fits were obtained (Fig. 3). The SD of all PSV values was calculated and plotted as error bars.

\section{RESULTS}

The data for the four experimental runs are presented in Table 1 and in Figure 3. Sample waveforms are illustrated in Figure 4. Note that for the moderate grade stenosis, the poststenotic PSV appeared nearly independent of compliance, decreasing only very slightly with decreasing compliance; for the low grade stenosis, the poststenotic PSV was mildly dependent on compliance, decreasing with decreasing compliance (Fig. 3).

From the linear regressions, the calculated poststenotic PSV values decreased, from normal renal vascular compliance to very low compliance, as 
follows: $24 \%$ decrease for low grade stenosis and normal renal vascular resistance (i.e., the calculated normalized PSV was 1.80 at normal compliance and 1.36 at very low compliance; the percentage decrease was therefore $[(1.80-$ $1.36) / 1.80] \times 100 \%=24 \%) ; 39 \%[(1.66-1.01) / 1.66]$ decrease for low grade stenosis and high renal vascular resistance; $10 \%$ [(9.18 - 8.28)/9.18] decrease for moderate grade stenosis and normal renal vascular resistance; and $7 \%[(6.31-5.86) / 6.31]$ decrease for moderate grade stenosis and high renal vascular resistance.

\section{DISCUSSION}

As fluid flows through a renal artery stenosis, a local velocity increase occurs. Many studies have evaluated the PSV12-25 for detection of hemodynamically significant renal artery stenosis. Unfortunately, the results have been less than satisfactory, ranging from $0 \%$ sensitivity and $37 \%$ specificity 13 to $98 \%$ sensitivity and specificity. ${ }^{22}$ Technical factors such as bowel gas and obesity (which obscure the renal artery) and accessory arteries (which may be stenosed but go undetected) are partially responsible but do not completely explain the discrepant results.

Figure 3 Plots of normalized PSV versus fraction of normal compliance, for low grade stenosis and normal renal vascular resistance (A), low grade stenosis and high vascular resistance (B), moderate grade stenosis and normal vascular resistance (C), and moderate grade stenosis and high vascular resistance (D). Data points include error bars ( \pm one standard deviation). Linear regressions were plotted to fit the data. PSV decreases mildly with decreasing compliance for all four modes of the experiment. The PSV values for both the low and moderate grade stenoses were slightly lower with high renal vascular resistance than with normal renal vascular resistance (compare $\mathbf{B}$ to $\mathbf{A}$ and $\mathbf{D}$ to $\mathbf{C}$ ). This suggests that the PSV is also dependent on distal vascular resistance. The effect of distal resistance has been investigated in detail in a separate study.40

A

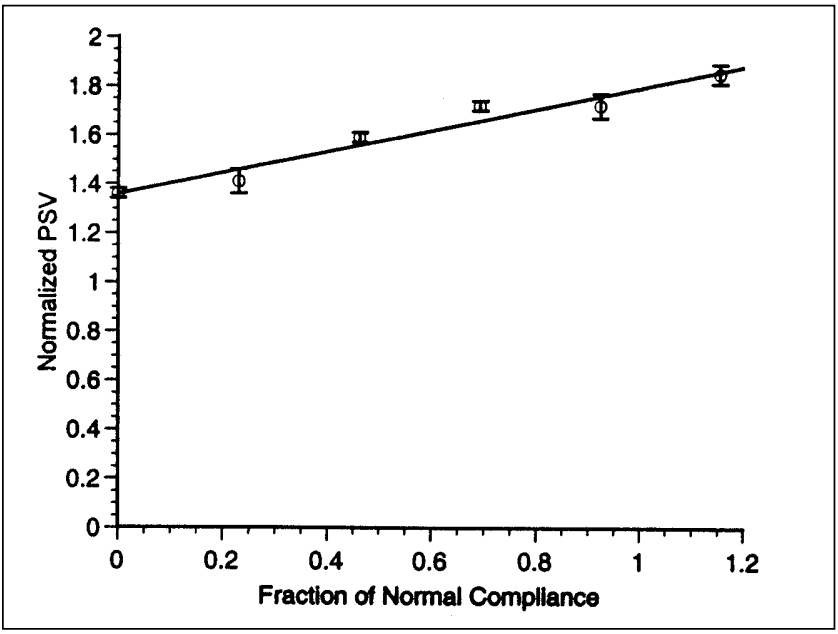

C

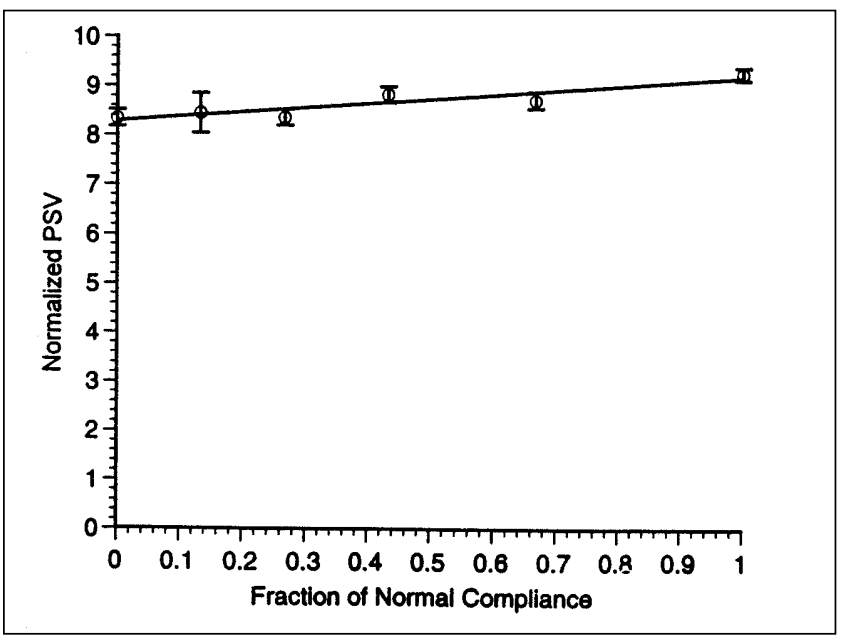

B

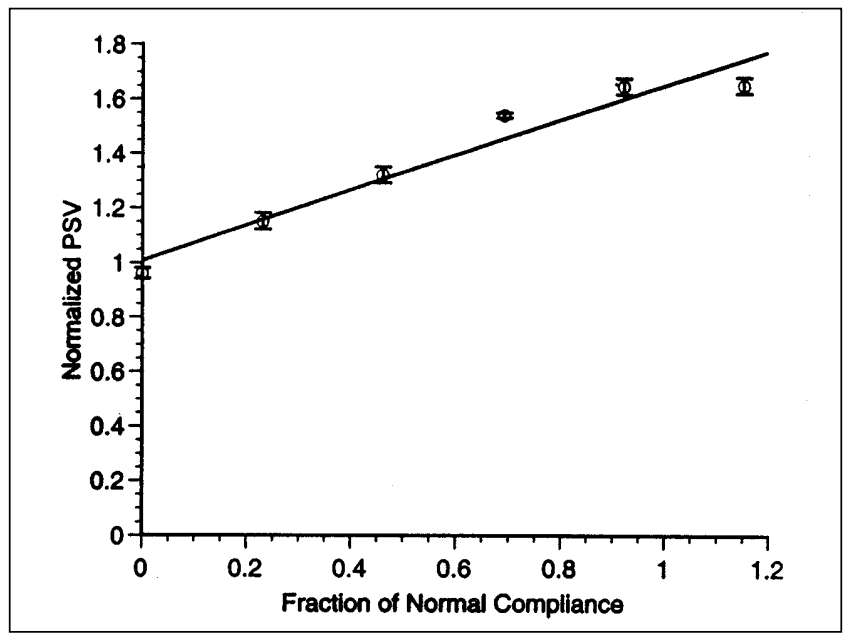

D

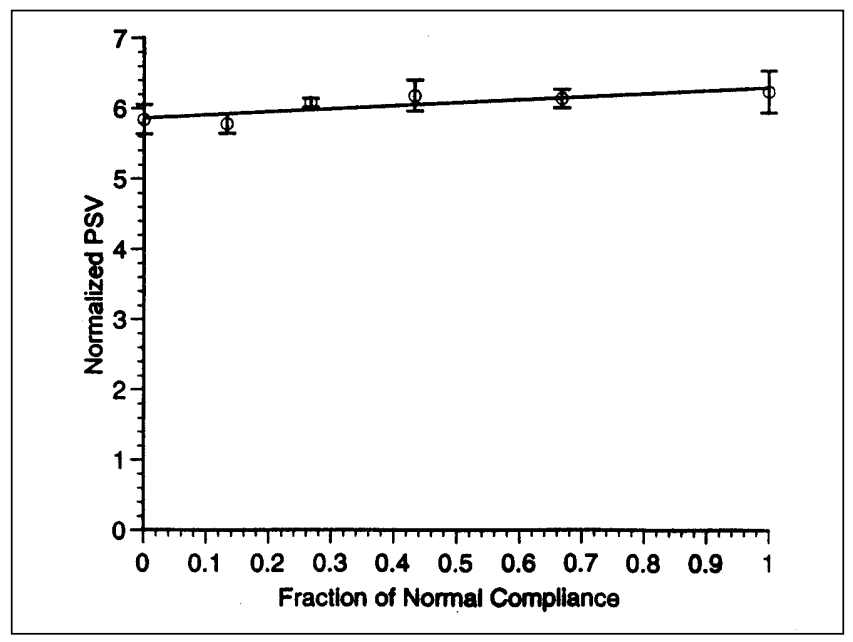


Table 1: Experimental Data

\begin{tabular}{|c|c|c|c|}
\hline $\begin{array}{l}\text { Poststenotic PSV, } \\
\mathrm{cm} / \mathrm{s}( \pm \mathrm{SD})\end{array}$ & $\begin{array}{l}\text { Aortic PSV, } \\
\mathrm{cm} / \mathrm{s}( \pm \mathrm{SD})\end{array}$ & $\begin{array}{c}\text { Poststenotic PSV, } \\
\text { normalized to aortic PSV }( \pm \text { SD })\end{array}$ & $\begin{array}{l}\text { Compliance as \% } \\
\text { of normal compliance }\end{array}$ \\
\hline \multicolumn{4}{|l|}{ Moderate grade stenosis with high vascular resistance } \\
\hline $476 \pm 17.0$ & $81.4 \pm 1.6$ & $5.85 \pm 0.21$ & 0 \\
\hline $480 \pm 11.5$ & $82.9 \pm 1.2$ & $5.79 \pm 0.14$ & 13.3 \\
\hline $511 \pm 5.1$ & $84.0 \pm 1.0$ & $6.08 \pm 0.06$ & 26.7 \\
\hline $513 \pm 18.3$ & $83.0 \pm 0.9$ & $6.18 \pm 0.22$ & 43.3 \\
\hline $523 \pm 10.8$ & $84.9 \pm 1.2$ & $6.16 \pm 0.13$ & 66.7 \\
\hline $529 \pm 25.6$ & $84.6 \pm 1.1$ & $6.25 \pm 0.30$ & 100 \\
\hline \multicolumn{4}{|l|}{ Moderate grade stenosis with normal vascular resistance } \\
\hline $648 \pm 13.5$ & $77.7 \pm 1.6$ & $8.34 \pm 0.17$ & 0 \\
\hline $692 \pm 32.5$ & $82.0 \pm 1.3$ & $8.44 \pm 0.40$ & 13.3 \\
\hline $694 \pm 12.9$ & $83.0^{*}$ & $8.36 \pm 0.16$ & 26.7 \\
\hline $741 \pm 13.7$ & $83.9 \pm 0.7$ & $8.83 \pm 0.16$ & 43.3 \\
\hline $737 \pm 14.0$ & $84.5 \pm 1.6$ & $8.72 \pm 0.17$ & 66.7 \\
\hline $749 \pm 10.7$ & $80.8 \pm 1.6$ & $9.27 \pm 0.13$ & 100 \\
\hline \multicolumn{4}{|l|}{ Low grade stenosis with high vascular resistance } \\
\hline $60.5 \pm 1.0$ & $62.7 \pm 0.7$ & $0.96 \pm 0.02$ & 0 \\
\hline $72.7 \pm 1.8$ & $63.4 \pm 1.2$ & $1.15 \pm 0.03$ & 23.1 \\
\hline $87.5 \pm 2.1$ & $66.3 \pm 0.5$ & $1.32 \pm 0.03$ & 46.2 \\
\hline $101 \pm 0.8$ & $65.3 \pm 0.4$ & $1.55 \pm 0.01$ & 69.2 \\
\hline $108 \pm 2.0$ & $65.2 \pm 1.1$ & $1.66 \pm 0.03$ & 92.3 \\
\hline $112 \pm 1.7$ & $67.6 \pm 0.4$ & $1.66 \pm 0.03$ & 115 \\
\hline \multicolumn{4}{|l|}{ Low grade stenosis with normal vascular resistance } \\
\hline $84.2 \pm 1.0$ & $62.1 \pm 0.7$ & $1.36 \pm 0.02$ & 0 \\
\hline $89.0 \pm 3.1$ & $63.2 \pm 0.6$ & $1.41 \pm 0.05$ & 23.1 \\
\hline $102 \pm 1.3$ & $63.9 \pm 0.6$ & $1.60 \pm 0.02$ & 46.2 \\
\hline $111 \pm 1.4$ & $64.7 \pm 0.4$ & $1.72 \pm 0.02$ & 69.2 \\
\hline $116 \pm 3.1$ & $67.5 \pm 0.3$ & $1.72 \pm 0.05$ & 92.3 \\
\hline $124 \pm 2.6$ & $66.7 \pm 1.0$ & $1.86 \pm 0.04$ & 115 \\
\hline
\end{tabular}

*This value was inadvertently not obtained; therefore the value listed is an interpolation between adjacent aortic PSV's.

Since vascular compliance affects the arterial waveform, ${ }^{1-4}$ and compliance varies in vivo, ${ }^{5-11}$ this study was performed to determine if vascular compliance affects the poststenotic PSV. If so, this may help explain the variable results using poststenotic PSV to detect stenoses. To make this evaluation, we studied the effect of varying the compliance from as low as possible to a level simulating that present normally in vivo, likely encompassing a greater range than is possible in vivo. This was done using two levels of renal vascular resistance, one simulating normal in vivo resistance, and one that is very high, which restricted volume flow to the kidney to only approximately one fifth of its normal value. These two values were chosen to encompass the range of resistances usually encountered in the evaluation for renal artery stenosis, not to completely study the effect of vascular resistance, which is the topic of a separate investigation, ${ }^{38}$ but to determine if vascular resistance substantially modifies the effect of vascular compliance.
Our results show that poststenotic PSV decreases only mildly with decreasing vascular compliance for both moderate and very low grade stenoses at both normal and very high grade renal vascular resistances. In vivo, vascular compliance is not constant but varies with blood pressure, age, and medications $\left.{ }^{5-11}\right)$. For example, human aortic compliance decreases by a factor of approximately 5 between normotensive persons 20 to 24 years old and hypertensive subjects in the eighth decade 6 and by a factor of approximately 3 between the ages of 10 and 60 years in normal persons as part of the aging process. 5 These in vivo compliance ranges encompass a large portion of the compliance range evaluated in our study and strongly suggest our in vitro results apply in vivo.

Our results are also highly likely to apply to another parameter used in stenosis detection, the RAR (RAR = stenotic PSV/aortic PSV26-30). This is because experimental evidence indicates aortic PSV is essentially independent of peripheral vascular resistance changes in vivo. ${ }^{39}$ Therefore, RAR should vary with compliance changes in the same manner as the stenotic PSV does. 
For detecting moderate or higher grade stenoses, the very mild dependence of stenotic PSV (Fig. 3) on vascular compliance is unlikely to be significant. This is because these degrees of stenosis are likely to produce fairly large PSV values, which exceed threshold levels enough that even if they are lowered slightly by a low compliance, they will still almost certainly exceed the detection threshold and not go undetected. The mild dependence of low grade stenoses with vascular compliance is a differ-

Figure 4 Sequence of poststenotic Doppler waveforms with the low grade stenosis and normal renal vascular resistance. Waveforms are numbered sequentially from lowest (1) to highest (6) vascular compliance. Compliance values, expressed in terms of percentage of compliance relative to normal compliance, were as follows: $0 \%$ for waveform 1 (A), $23.1 \%$ for waveform 2 (B), 46.2\% for waveform 3 (C), 69.2\% for waveform 4 (D), 92.3\% for waveform 5 (E), and 115\% for waveform 6 (F). PSV increases slightly from lowest to highest compliance.

A

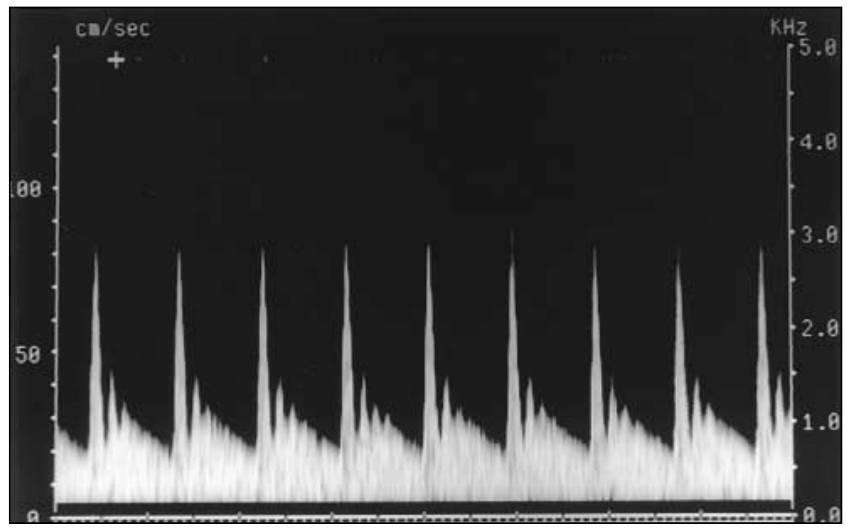

C

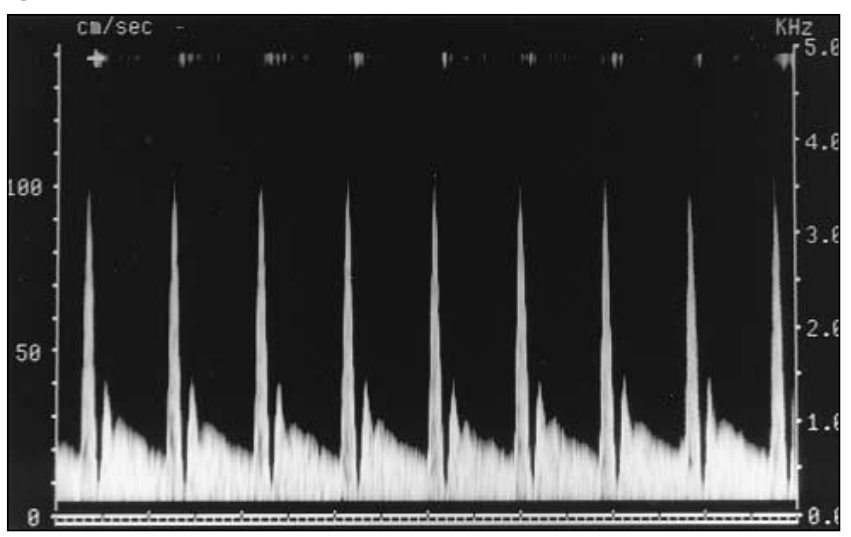

$\mathbf{E}$

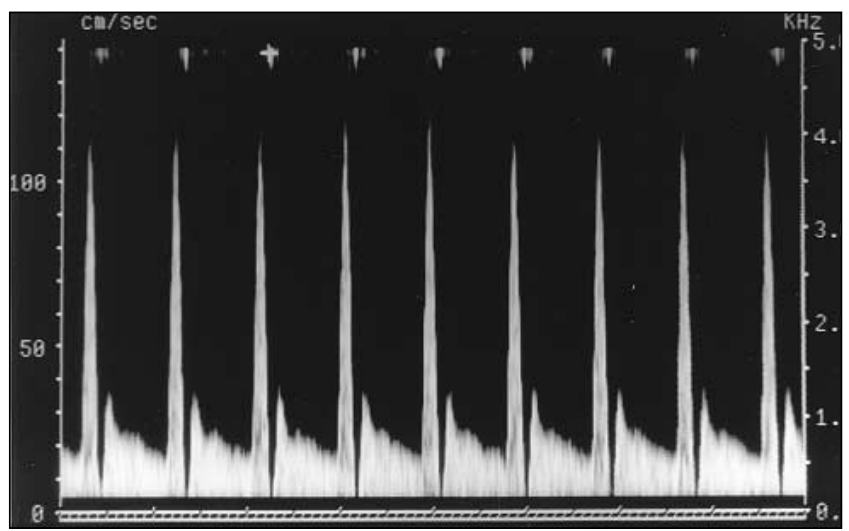

B

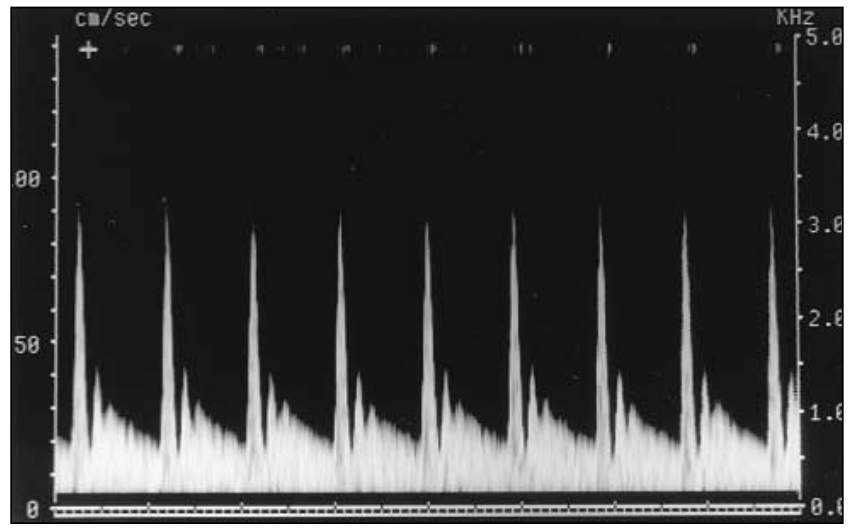

D

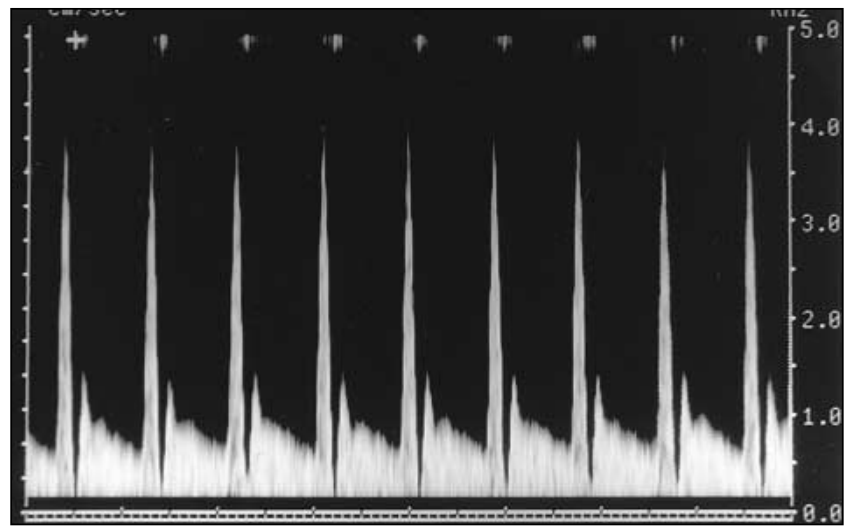

F

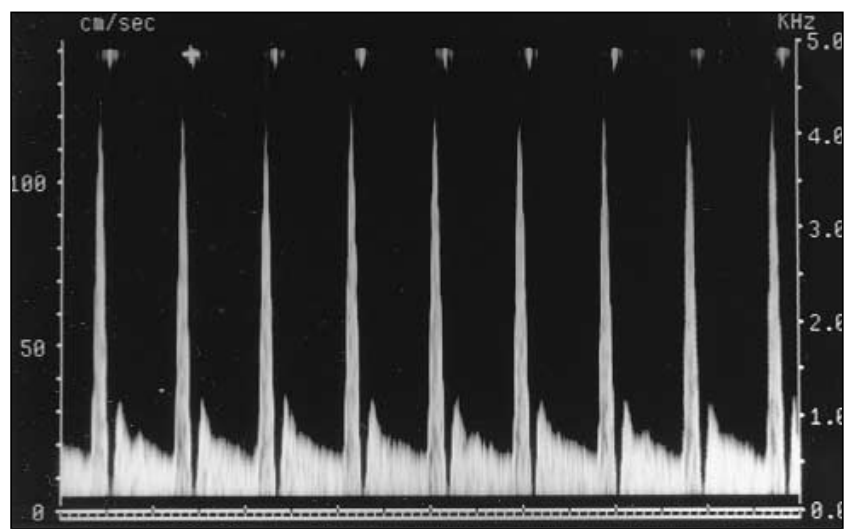


ent matter. Consider our low grade stenosis. Although it is not quite significant hemodynamically, it is much nearer the hemodynamically significant range than it is to the moderate stenosis also evaluated in our experiment, and we believe our results for the low grade stenosis are highly likely to apply to slightly greater in vivo stenoses at the threshold of hemodynamic significance. For our low grade stenosis at normal renal vascular resistance, the poststenotic PSV at a compliance of one fifth of normal (which is within the compliance range possible in vivo) is $19 \%$ less than the poststenotic PSV at normal compliance (Fig. 3) (normalized PSV at normal compliance $=1.80$; normalized PSV at one-fifth normal compliance $=1.45$; $\%$ decrease $=([1.80-1.45 / 1.80][100 \%]=19 \%) . \mathrm{A}$ similar calculation for the low grade stenosis at high renal vascular resistance gives a poststenotic PSV that is $31 \%$ less than at normal compliance (normalized PSV at normal compliance $=1.66$; normalized PSV at one-fifth normal compliance $=1.14$; $\%$ decrease $=([1.66-1.14 / 1.66][100 \%]=31 \%)$. Thus, in our model, if a velocity threshold of 100 $\mathrm{cm} / \mathrm{s}$ is used for stenosis detection at normal renal vascular resistance, any stenosis producing a PSV of up to approximately $123 \mathrm{~cm} / \mathrm{s}$ at normal compliance produces a PSV of less than $100 \mathrm{~cm} / \mathrm{s}$ at onefifth normal compliance $(123 \times[100 \%-19 \%]=100)$. Similarly, at high renal vascular resistance in our model, any stenosis producing a PSV of up to 145 $\mathrm{cm} / \mathrm{s}$ at normal compliance produces a PSV of less than approximately $100 \mathrm{~cm} / \mathrm{s}$ at one fifth of normal compliance $(145 \times[100 \%-31 \%]=100)$. These results thus help explain some of the false-negative results when PSV is used to detect hemodynamically significant stenoses. They do not provide a complete explanation, however, since the reported PSV thresholds for detecting hemodynamically significant stenoses vary substantially more than the just-described ranges (100 to $350 \mathrm{~cm} / \mathrm{s}$ ). Other factors not evaluated in our study must be at work as well.

Our study has two limitations. First, it is an in vitro study. Therefore, even though our compliances and resistances produced the same magnitude of effects as are present in vivo, our model does not duplicate in vivo conditions. Therefore, our results can only be used to help explain, and not directly extrapolate to, the in vivo situation. Second, the "normal" compliances used in our study were slightly less than actually occur in vivo, because our "normal" compliance values damped the pulsatility of the downstream renal artery waveform to an RI of 0.2 instead of 0.0 as occurs in vivo. However, our study shows that the PSV is only mildly dependent on compliance, and even if slightly higher values of compliance had been used in our experiment, it is highly unlikely the results would have been substantially different from those we observed.

In conclusion, PSV is mildly dependent on vascular compliance, decreasing with decreasing vascular compliance. The results of this experiment help explain some of the reported variability using PSV to detect hemodynamically significant renal artery stenoses, but the effect is not great enough to explain the variability completely. It is likely that differences in operator skills and differences in the degree of dedication to meticulous technique among observers play substantial roles in this variability. Other factors may be at work as well.

\section{REFERENCES}

1. Nichols WW, O'Rourke MF: Introduction. In Nichols WW, O'Rourke MF (Eds): McDonald's Blood Flow in Arteries: Theoretic, Experimental and Clinical Principles. 4th Ed. New York, Oxford University Press, 1998, p 3

2. Nichols WW, O'Rourke MF: Coupling of the left ventricle with the systemic circulation: Implications to cardiac failure. In Nichols WW, O'Rourke MF (Eds): McDonald's Blood Flow in Arteries: Theoretic, Experimental and Clinical Principles. 4th Ed. New York, Oxford University Press, 1998, p 295

3. McDonald DA, Taylor MG: The hydrodynamics of the arterial circulation. Progr Biophys Chem 9:107, 1959

4. Halpern EJ, Deane CR, Needleman L, et al: Normal renal artery spectral Doppler waveform: A closer look. Radiology 196:667, 1995

5. Lehmann ED, Hopkins KD, Gosling RG: Aortic compliance measurements using Doppler ultrasound: In vivo biochemical correlates. Ultrasound Med Biol 19:683, 1993

6. Hallock P, Benson IC: Studies on the elastic properties of human isolated aorta. J Clin Invest 16:595, 1937

7. Safar ME, Laurent SL, Bouthier JD, et al: Effect of converting enzyme inhibitors on hypertensive large arteries in humans. J Hypertens 4(Suppl 5):S285, 1986

8. Marchais SJ, Geurin AP, Pannier B, et al: Arterial compliance and blood pressure. Drugs 46(Suppl 2):82, 1993

9. Nichols WW, O'Rourke MF: Properties of the arterial wall. In Nichols WW, O'Rourke MF (Eds): McDonald's Blood Flow in Arteries: Theoretic, Experimental and Clinical Principles. 3rd Ed. Philadelphia, Lea \& Febiger, 1990, p 77

10. Roy CS: The elastic properties of the arterial wall. J Physiol (Lond) 3:125, 1880

11. Avolio AP, Deng FQ, Li WQ, et al: Effects of aging on arterial distensibility in populations with high and low prevalence of hypertension: Comparison between urban and rural communities in China. Circulation 71:202, 1985 
12. Avasthi PS, Voyles WF, Greene ER: Noninvasive diagnosis of renal artery stenosis by echo-Doppler velocimetry. Kidney Int 25:824, 1984

13. Berland LL, Koslin DB, Routh WD, et al: Renal artery stenosis: Prospective evaluation of diagnosis with color duplex US compared with angiography. Radiology 174:421, 1990

14. Desberg AL, Paushter DM, Lammert GK, et al: Renal artery stenosis: Evaluation with color Doppler flow imaging. Radiology 177:749, 1990

15. Duda SH, ErleyCM, Wakat JP, et al: Post transplant renal artery stenosis-Outpatient intraarterial DSA versus color aided duplex Doppler sonography. Eur J Radiol 16:95, 1993

16. Kliewer MA, Tupler RH, Carroll BA, et al: Renal artery stenosis: Analysis of Doppler waveform parameters and tardus-parvus pattern. Radiology 189:779, 1993

17. Saarinen O, Salmela K, Edgren J: Doppler ultrasound in the diagnosis of renal transplant artery stenosis: Value of resistive index. Acta Radiol 35:586, 1994

18. Baxter GM, Ireland H, Moss JG, et al: Colour Doppler ultrasound in renal transplant artery stenosis: Which Doppler index? Clin Radiol 50:618, 1995

19. Gottlieb RH, Lieberman JL, Pabico RC, et al: Diagnosis of renal artery stenosis in transplanted kidneys: Value of Doppler waveform analysis of the intrarenal arteries. AJR 165:1441, 1995

20. Helenon O, Rody FE, Correas JM, et al: Color Doppler US of renovascular disease in native kidneys. RadioGraphics 15:833, 1995

21. Hoffman U, Edwards JM, Carter S, et al: Role of duplex scanning for the detection of atherosclerotic renal artery disease. Kidney Int 39:1232, 1991

22. Olin JW, Piedmonte R, Young JR, et al: The utility of duplex ultrasound scanning of the renal arteries for diagnosing significant renal artery stenosis. Ann Intern Med 122:833, 1995

23. Strotzer M, Fellner CM, Geissler A, et al: Noninvasive assessment of renal artery stenosis: A comparison of MR angiography, color Doppler sonography, and intraarterial angiography. Acta Radiol 36:243, 1995

24. Miralles M, Cairols C, Cotillas J, et al: Value of Doppler parameters in the diagnosis of renal artery stenosis. J Vasc Surg 23:428, 1996

25. van der Hulst V PM, van Baalen, J, Kool LS, et al: Renal artery stenosis: Endovascular flow wire study for validation of Doppler US. Radiology 200:165, 1996

26. Merkus JWS, Hoitsma AJ, van Asten WNJC, et al: EchoDoppler diagnosis of renal allograft artery stenosis. Clin Transplant 9:383, 1995

27. Taylor DC, Kettler MD, Moneta GL, et al: Duplex ultrasound scanning in the diagnosis of renal artery stenosis: A prospective evaluation. J Vasc Surg 7:363, 1988

28. Hansen KJ, Tribble RW, Reavis SW, et al: Renal duplex sonography: Evaluation of clinical utility. J Vasc Surg $12: 227,1990$

29. Kohler TR, Zierler E, Martin RL, et al: Non-invasive diagnosis of renal artery stenosis by ultrasonic duplex scan- ning. J Vasc Surg 4:450, 1986

30. Halpern EJ, Needleman L, Nack TL, et al: Renal artery stenosis: Should we study the main renal artery or segmental vessels? Radiology 195:799, 1995

31. Bude RO, Rubin JM, Platt JF, et al: Pulsus tardus: Its cause and potential limitations in detection of arterial stenosis. Radiology 190:779, 1994

32. Folkow B, Neil E: General principles. In Circulation. New York, Oxford University Press, 1971, p 10

33. Nichols WW, O'Rourke MF: The nature of flow of a fluid. In Nichols WW, O'Rourke MF (Eds): McDonald's Blood Flow in Arteries: Theoretic, Experimental and Clinical Principles. 4th Ed. New York: Oxford University Press, 1998, p 11

34. Nichols WW, O'Rourke MF: Introduction. In Nichols WW, O'Rourke MF (Eds): McDonald's Blood Flow in Arteries: Theoretic, Experimental and Clinical Principles. 4th Ed. New York, Oxford University Press, 1998, p 1

35. Nichols WW, O'Rourke MF: The nature of flow of a fluid. In Nichols WW, O'Rourke MF (Eds): McDonald's Blood Flow in Arteries: Theoretic, Experimental and Clinical Principles. 4th Ed. New York, Oxford University Press, 1998, p 40

36. Duck FA: Mechanical properties of tissue. In Physical Properties of Tissue. San Diego: Academic Press, 1990, p 161

37. Weast RC (Ed): Handbook of Chemistry and Physics. 52nd Ed. Cleveland, The Chemical Rubber Company, 1971-1972, p D191

38. Bude RO, Larson RC, Nichols WM, et al: Stenosis of the main artery supplying an organ: Effect of end-organ vascular resistance on the post-stenotic peak systolic velocity in an in vitro hydraulic model at Doppler US. Radiology 212:79, 1999

39. Westerhof N, Sipkema P, Bos GC, et al: Forward and backward waves in the arterial system. Cardiovasc Res $6: 648,1972$

\section{APPENDIX}

Vascular compliance is defined as a change in volume produced by a change in pressure, and is defined as $\Delta \mathrm{V} / \Delta \mathrm{P}$. Arterial expansion during systole with subsequent relaxation or contraction during diastole are manifestations of this phenomenon.

In our model, vascular compliance of the renal artery was concentrated in one region, the Windkessel. Compliance could not be directly measured, but was assumed proportional to the amount of air in the Windkessel due to the following line of reasoning.

Gases, including air, under normal conditions follow a simple relationship known as Boyle's law: $\mathrm{PV}=\mathrm{k}$, where $\mathrm{P}$ is pressure, $\mathrm{V}$ is volume, and $\mathrm{k}$ is a constant. Thus, for example, when the pressure exerted upon a volume of gas doubles and all other 
factors remain constant, the volume of gas decreases by half.

Consider two Windkessels, \#1 and \#2, containing different volumes of air but otherwise alike and under the same conditions, including pressure. The initial conditions for $\# 1$ are $V_{1}$ and $P_{1}$ and the initial conditions for \#2 are $V_{3}$ and also $P_{1}$. Each follows Boyle's law so that:

$$
\begin{aligned}
\mathrm{P}_{1} \mathrm{~V}_{1} & =\mathrm{k}_{\# 1} \\
\text { and } \mathrm{P}_{1} \mathrm{~V}_{3} & =\mathrm{k}_{\# 2}
\end{aligned}
$$

Now assume that each Windkessel is subjected to a new pressure, $P_{2}$, that is the same for both Windkessels. Since Boyle's law states that, assuming constant temperature, the product PV is constant, for Windkessel \#1:

$$
\mathrm{P}_{1} \mathrm{~V}_{1}=\mathrm{P}_{2} \mathrm{~V}_{2}
$$

and for Windkessel \#2:

$$
\mathrm{P}_{1} \mathrm{~V}_{3}=\mathrm{P}_{2} \mathrm{~V}_{4}
$$

These equations rearrange to:

$$
\begin{aligned}
\mathrm{V}_{2} / \mathrm{V}_{1} & =\mathrm{P}_{1} / \mathrm{P}_{2} \\
\text { and } \mathrm{V}_{4} / \mathrm{V}_{3} & =\mathrm{P}_{1} / \mathrm{P}_{2}
\end{aligned}
$$

Thus,

$$
\mathrm{V}_{2} / \mathrm{V}_{1}=\mathrm{V}_{4} / \mathrm{V}_{3}
$$

Now, as stated earlier, $V_{3}$ is different than $V_{1}$. Let $n$ equal the ratio of $V_{3}$ to $V_{1}$, i.e.,

$$
\mathrm{V}_{3}=\mathrm{nV}_{1}
$$

Substituting $\mathrm{nV}_{1}$ for $\mathrm{V}_{3}$ in equation 7 and rearranging terms, it can be seen that

$$
\mathrm{V}_{4}=\mathrm{nV}_{2}
$$

As earlier described, compliance, $\mathrm{C}$, equals $\Delta \mathrm{V} / \Delta \mathrm{P}$. Therefore

$$
\mathrm{C}_{\# 1}=\Delta \mathrm{V}_{\# 1} / \Delta \mathrm{P}=\left(\mathrm{V}_{2}-\mathrm{V}_{1}\right) /\left(\mathrm{P}_{2}-\mathrm{P}_{1}\right)
$$

and using equations 8 and 9,

$$
\begin{aligned}
\mathrm{C}_{\# 2} & =\Delta \mathrm{V}_{\# 2} / \Delta \mathrm{P}=\left(\mathrm{V}_{4}-\mathrm{V}_{3}\right) /\left(\mathrm{P}_{2}-\mathrm{P}_{1}\right) \\
& =\left(n V_{2}-\mathrm{nV}_{1}\right) /\left(\mathrm{P}_{2}-\mathrm{P}_{1}\right)=\mathrm{n}\left(\mathrm{V}_{2}-\mathrm{V}_{1}\right) /\left(\mathrm{P}_{2}-\mathrm{P}_{1}\right)
\end{aligned}
$$

Therefore, the ratio of compliances, $C_{\# 2} / C_{\# 1}$, is obtained by dividing equation 11 by equation 10, giving

$$
\mathrm{C}_{\# 2} / \mathrm{C}_{\# 1}=\left[\mathrm{n}\left(\mathrm{V}_{2}-\mathrm{V}_{1}\right) /\left(\mathrm{P}_{2}-\mathrm{P}_{1}\right)\right] /\left[\left(\mathrm{V}_{2}-\mathrm{V}_{1}\right) /\left(\mathrm{P}_{2}-\mathrm{P}_{1}\right)\right]
$$

which reduces to

$$
\mathrm{C}_{\# 2} / \mathrm{C}_{\# 1}=\mathrm{n}
$$

Equation 13 shows that the compliance in two Windkessels which are otherwise alike except for their initial volumes is proportional to the amount of air within them. 